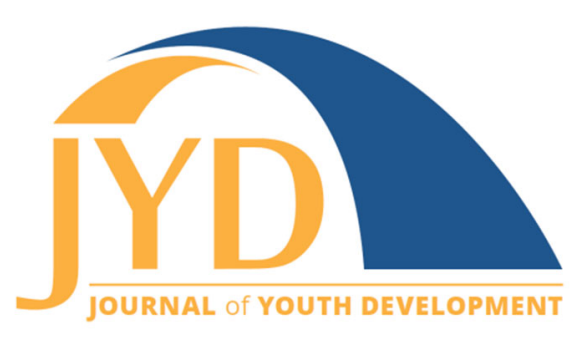

http://jyd.pitt.edu/ | Vol. 15 Issue 5 DOI 10.5195/jyd.2020.796 | ISSN 2325-4017 (online)

\title{
Build Your Future: Connecting Career Exploration and Postsecondary Education
}

\author{
Nancy Shelstad \\ University of Idaho \\ shelstad@uidaho.edu \\ Carrie Johnson \\ University of Idaho \\ carriej@uidaho.edu \\ Suzann Dolecheck \\ University of Idaho \\ sdolecheck@uidaho.edu
}

\begin{abstract}
Many factors perpetuate the low go-on rate in Idaho, and many Idaho youth do not look to postsecondary education as an obtainable future, though evidence predicts Idaho's job market will require more postsecondary degrees. Therefore, the goal of the Idaho 4-H Build Your Future Program is to cultivate relationships with Idaho youth that would otherwise not seek postsecondary education. The program provides youth with the opportunity to explore career options, visit a college campus, and visualize themselves as capable, competent adults with a quality education, thus inspiring more youth to consider pursuing advanced career paths. Site facilitators across Idaho led groups of youth in $8^{\text {th }}$ through $12^{\text {th }}$ grades through the program. A pre-post retrospective survey of the 2018 program indicates that youth are learning more about postsecondary education options and how to pay for it. In the survey, $87 \%$ of youth indicated that they understand the different requirements for postsecondary degrees and certifications, and $77 \%$ indicated that they have created a plan to pay for their postsecondary education. The program is raising awareness of potential solutions for moving forward with postsecondary education options.
\end{abstract}

Key words: college readiness, career exploration, postsecondary education, 4- $\mathrm{H}$, youth financial education

(cc) EY New articles in this journal are licensed under a Creative Commons Attribution 4.0 License. This journal is published by the University Library System, University of Pittsburgh and is cosponsored by the University of Pittsburgh Press. The Journal of Youth Development is the official peer-reviewed publication of the National Association of Extension 4-H Youth Development Professionals and the National AfterSchool Association. 


\section{Introduction}

Only 45\% of Idaho's 2017 high school graduates enrolled in college within a year of receiving their high school diploma (Clark, 2018). This is one of the lowest go-on rates in the nation, which creates a challenge in Idaho because by 2022 postsecondary education will be required for $60 \%$ of projected job openings, and $27 \%$ will require a bachelor's degree or greater (Idaho Department of Labor, 2018). Therefore, it is important for Idaho's youth to recognize the value of a postsecondary education and continue their education beyond high school to be successful in the job market. Factors contributing to the low percentage of Idaho youth going on to college include placing a high priority on serving in the military or being active in their church; attitudes and values about finding a job they love and being near family; the ability to afford more school; and being a member of the Hispanic population, Idaho's largest minority group (Henscheld \& McHugh, 2017). Factors specifically affecting the Hispanic population include level of educational attainment by their parents, concerns about qualifying for scholarships, and understanding of long-term personal financial benefits of postsecondary education (Henscheld \& McHugh, 2017).

School staff and faculty, community leaders, and state leaders are looking for ways to improve the Idaho go-on rate, and it is no longer just a matter of increasing the number of college fairs in school districts. A study by Schneider et al. (2013) shows that programs encouraging postsecondary education need to start by at least the eighth grade, address financial concerns including filling out the Free Application for Federal Student Aid (FAFSA), familiarize youth with college campuses, and include education regarding multiple postsecondary educational opportunities. Creating a "college-going culture" that allows youth to see themselves going to college, have a plan for how to make it happen, and have the support of school personnel and family is essential for youth who may not have considered attending college in the past (Schneider et al., 2013). For many young people in Idaho, this means starting at the first level of Hossler \& Gallagher's (1987) three-stage model of college choice: predisposition. In this first stage, students form their attitudes toward college and begin to determine if attending college is a path they want to pursue. Socioeconomic status, student achievement, and influence from parents and peers can strongly affect a student's attitude toward college in the predisposition stage.

In response to these needs Idaho 4-H Youth Development designed and implemented a program based on the National 4-H curriculum "Build Your Future: Skills . . . Choices . . . Careers" (Barrett et al., 2013) titled "Build Your Future: Connecting Career Exploration and 
Postsecondary Education" (BYF). Activities in this curriculum target predisposition and exploring careers. In addition to the curriculum, the Idaho BYF program includes youth financial education activities and a chance to visit a college campus. These combined elements provide youth an opportunity to reconsider their thoughts and attitudes about college as a possibility for their future.

\section{Program Development}

The original Idaho BYF program was piloted in the spring of 2017 using only the National 4-H curriculum. This curriculum provided youth an opportunity to take an active role in determining their future. Youth participating in this program were led through processes to discover their personal strengths and interests, careers they might be interested in, and the level of education needed for those careers. Participants learned how continued education and training beyond high school affects employment, earning potential, and lifetime earnings. Youth who participated in at least four of the first five Build Your Future curriculum activities of the National 4-H curriculum had the opportunity to attend the 2017 Idaho 4-H State Teen Association Convention (STAC) on the University of Idaho campus at no cost.

Feedback from the pilot year indicated youth concerns regarding managing finances and paying for college. To address these concerns, we supplemented the curriculum with additional financial education lessons tailored to Idaho youth that included paying for college and personal financial education in the 2018 program. Scholarship Worknight, Northwest Youth Financial Education series, and other youth financial education programs adopted by the University of Idaho offer eight options for facilitators to choose from to use at their specific site.

To further enhance the program and provide an additional important motivating component to youth, the opportunity to visit any Idaho college or university campus was also added in 2018. Visiting a college campus and connecting directly with college faculty and experiencing the university atmosphere can be influential in the decision to attend college. Cates \& Schaefle (2011) found that students ranked visiting a college campus as the most influential element in their decision to attend college. Therefore, this opportunity is available to all youth participating in the program and is in addition to attending STAC on the University of Idaho campus.

The BYF program targets high school students, ages 14 to 18 years old, with an emphasis on youth who may not have previously considered postsecondary education as an option. Youth 
may be first-generation college students, low income, rural and/or minority audiences, and firstgeneration 4-H families. To improve the go-on rate in Idaho, we included first-generation 4-H families as part of the target audience because we know that 4-H youth tend to have higher goon rates than non-4-H youth (Lerner et al., 2013).

The revised BYF program consists of three components:

1. Five learning activities from the Build Your Future curriculum:

- Skills ... Choices ... . Careers: Connecting experiences, personal interests, skills, values, and personality to career options and college majors.

- Making Career Connections: Increasing knowledge of careers by researching and exploring careers through interviews, internships and volunteering.

- Build Your Future Through Portfolios: Learning about career and employment portfolios and following the steps to create their own portfolio.

- Education Pay\$: Exploring how education and training affect employment opportunities, earning potential, and lifetime earnings.

- Career FUNds: Understanding the various types of postsecondary education and training, plus ways to fund it.

2. Two youth personal finance learning activities: Facilitators can choose two activities, based on site-specific needs, from the Northwest Youth Financial Education series which are designed to increase financial literacy among youth and young adults. Activity choices include InTuition, Night of the Living Debt, Who Wants to be a Credit Score Millionaire, Levy Gulch, Teens Credit Card, and Interstellar Investor. Welcome to the Real World and the University of Idaho Scholarship Work Night are also options.

3. An optional opportunity to visit a local college or university campus.

In addition to the learning experiences and activities, youth who meet participation criteria (completing at least $75 \%$ of the activities) may attend STAC held on the University of Idaho campus in Moscow, Idaho at no cost.

\section{Purpose and Expectations}

The goal of this program is to build relationships with Idaho youth who often do not consider postsecondary education in their future, thus providing the opportunity for these youth to develop skills while exploring career paths, visit the University of Idaho campus, and learn about the financial return on investment of a postsecondary education. While many obstacles 
still exist, by helping youth understand the value of a postsecondary education and providing an opportunity to experience a campus visit, the program aims to reduce the number of hurdles that many youth need to overcome when making choices about their postsecondary education.

In support of the overall program goals, short-term goals for program participants include exploring career paths and visualizing how a quality education can support their future. Intermediate goals for the program participants include a visit to the University of Idaho campus during the STAC event to experience campus housing, dining, and navigating the layout of a typical university campus. With this additional experience, we anticipate that youth will be more inclined to register, enroll, and attend a postsecondary institution that will serve them in pursuing their career choice. The long-term goal for participants is their completion of their postsecondary education that will serve as a tool for them to increase their career opportunities and earning potential.

\section{Support for Success}

BYF program managers work with county Extension professionals to identify program delivery sites and facilitators across Idaho. Program locations are primarily schools that are existing Extension partners and are led either as out-of-school programs or as part of class time teaching. Site facilitators are typically schoolteachers, counselors, or after-school programming staff; Extension professionals facilitate at a small number of locations. Each site facilitator agrees to a position description and is asked to recruit 20 youth to participate in the program at their location.

BYF program managers provide facilitators with the program structure, copies of the Build Your Future youth journal and facilitator guide, funding for programming supplies (up to \$175), funding for travel to a postsecondary institution (up to $\$ 400$ ), facilitator training, funding for STAC scholarships, and impact data for specific counties. Program support includes providing any required forms and responding to facilitators' questions and concerns. BYF program managers aid with financial reimbursements for program supplies and travel to a postsecondary facility. Before facilitators begin programming, they are given copies of registration forms, an attendance sheet, printed assessment surveys for each lesson, curriculum, a facilitator guide, and pre-addressed envelopes with postage to return surveys. 


\section{Measuring Successes}

Facilitators are provided instruction for administering the assessment surveys using the prepost retrospective method. The retrospective method of assessment reduces the response shift bias that research shows is present with traditional pre and post assessments (Howard, 1980). By using this assessment method, responses to both the pre and post assessment are given from the same understanding of the statement before the activity and understanding of the statement after the activity. In addition, Howard (1980) found that an objective measurement of change is more highly correlated with the retrospective pre-post self-reported change than the traditional pre-post self-reported change. The assessment surveys were approved by the University of Idaho Internal Review Board as exempt before the first year that the BYF program was implemented. Youth completed a pre-post retrospective survey from the Build Your Future curriculum after each learning activity. A separate survey was created to measure the level of understanding of the youth financial education activity learning objectives.

The surveys were distributed to the youth at the conclusion of the learning activity and they were asked to complete their responses to each learning indicator statement of their level of agreement after the activity and level of agreement of the statement before the activity. Surveys consisted of three to five indicator statements related to the learning objectives of each activity. The youth were asked to rank each statement for before and after the activity as strongly disagree, disagree, agree, or strongly agree. Facilitators returned the surveys to the program managers after each activity. Data from all sites was combined to show overall program impact although county data is available separately if the county requests.

While the increase in percentage of youth who agree or strongly agree with the statements varies, all the indicators show an increase, and in nearly all cases, they show a substantial increase. The $n$ of each response varied due to the number of youths participating in each learning activity and completeness of each survey.

Overall, Activities 3 and 5 show the highest increase in agreement with the indicator statements as shown in Figure 1. The learning outcomes of Activity 3 are (a) youth will know the difference between a career portfolio and an employment portfolio and (b) youth will list the components of either a career portfolio or an employment portfolio. The indicator statements in Figure 1 show a strong understanding of both learning outcomes although fewer have collected the needed reference letters and created a portfolio. 
The learning outcomes of Activity 5 are (a) youth will understand various types of postsecondary training institutions, (b) youth will know about types of certification awarded through postsecondary training, (c) youth will know the training and certification required for their career field of interest, (d) youth will understand various methods and options for paying for postsecondary education, and (e) youth will create a plan to pay for their postsecondary education. A high percentage of youth participants indicated that they agree or strongly agree with all the indicator statements to meet these outcomes. The figures below show the total percentage of youth who agreed or strongly agreed with the indicator statements before participating in the activity in the top bar and after participating in the activity in the bottom bar.

Figure 1. Survey of Learning Objectives, Activities 3 and 5

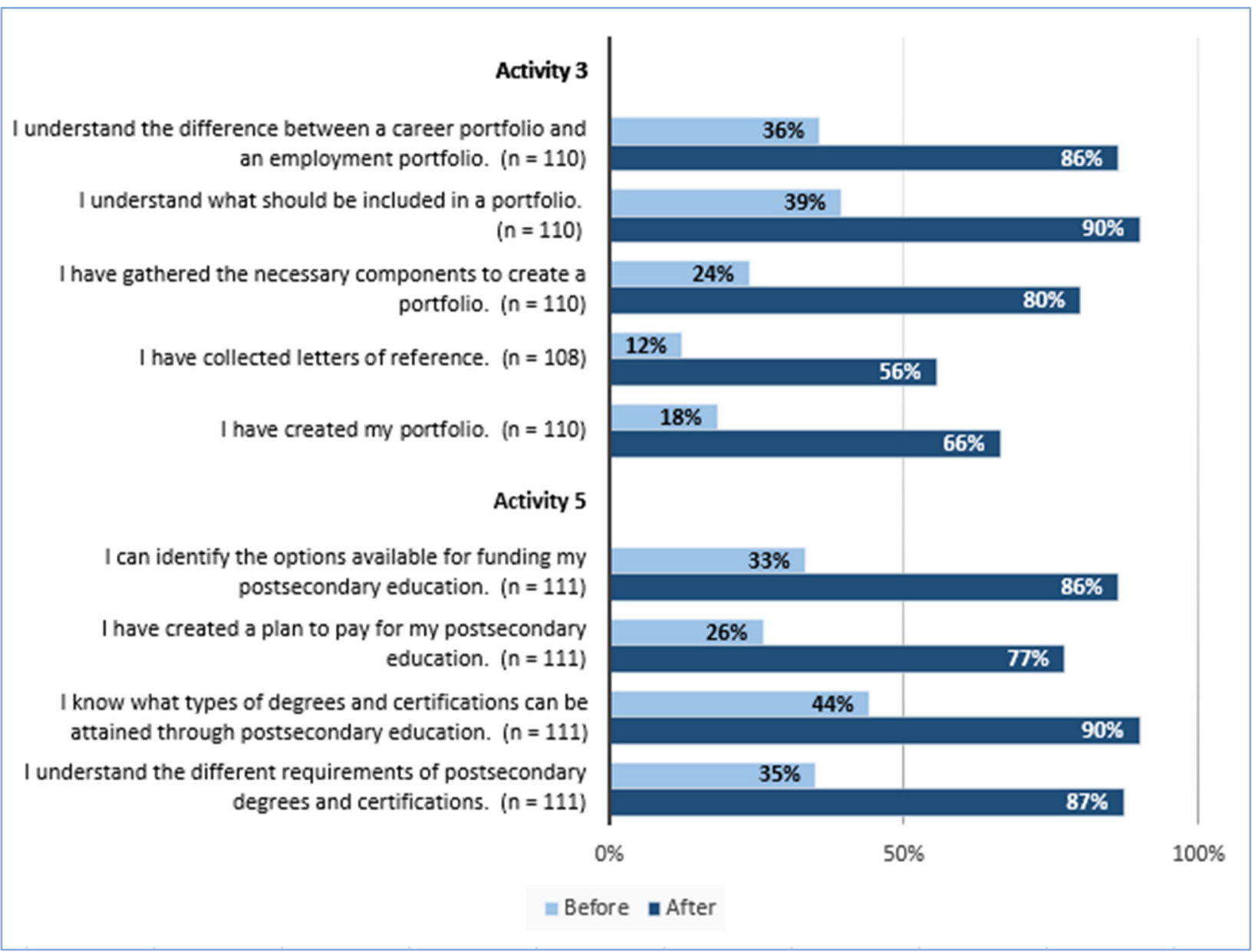


The learning outcomes of Activity 4 are (a) Youth will understand how education and training affect employment opportunities, earning potential, and lifetime earnings; and (b) Youth will explore how employee benefits add value to the money they earn. Survey results of Activity 4 in Figure 2 indicate that the youth started at a higher level of understanding and awareness before participating in the activity. As a result, the amount of increase between before and after the activity is not as great as the other activities, though it still shows an increase.

\section{Figure 2. Survey of Learning Objectives, Activity 4}

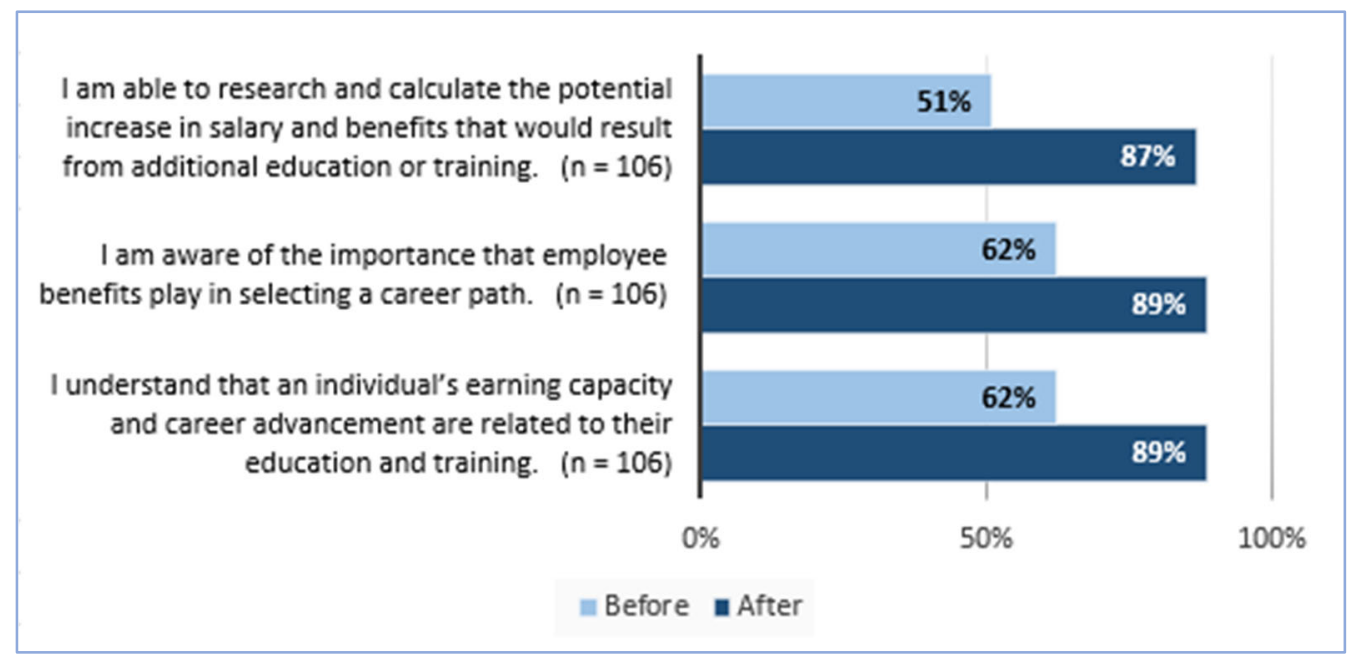

The Activity 1 learning outcome is that youth will connect their 4-H or extracurricular experiences, personal interests, skills, values, and personality to career options and college majors. The Activity 2 learning outcome is that youth will increase their knowledge of careers by researching and exploring careers through various methods. In this activity, youth interview and job shadow workers in career fields of interest. Because of remote locations of the program, in-person access to qualified professionals was limited which reduced the activity completion rate. Activities 1 and 2 showed the lowest percent increase; however, they still indicated an increase in knowledge. The majority of the survey results for Activities 1 and 2 also had a higher beginning level of understanding and awareness than Activities 3 and 5, which contributed to the lower percentage increase when comparing before and after responses. Preactivity responses indicate youth had prior knowledge in career areas of personal interest. Survey results in Figure 3 also indicate an increase in knowledge of specific education, skills, and characteristics needed to be successful in a career. 
Figure 3. Survey of Learning Objectives, Activities 1 and 2

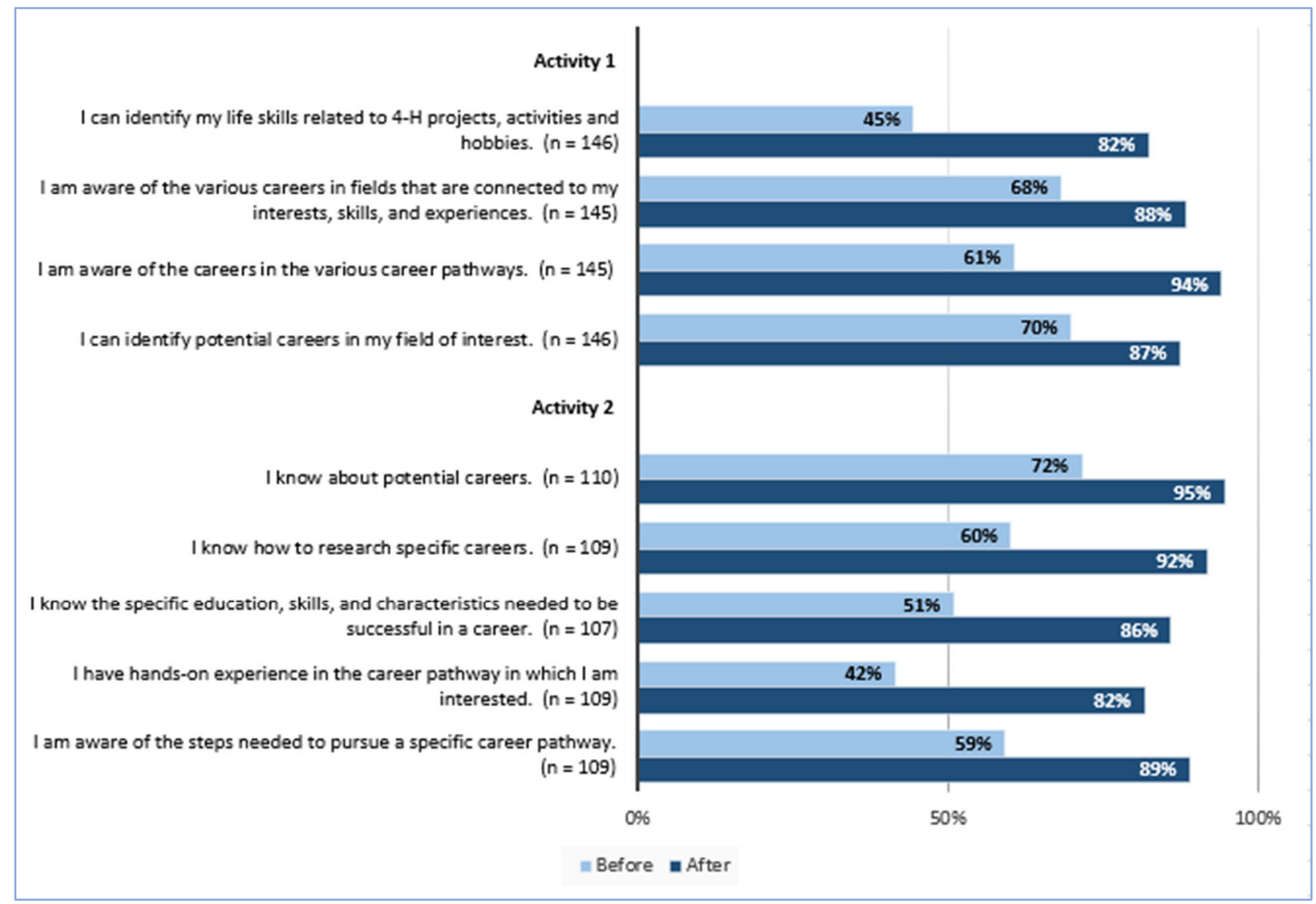

The survey results from the financial education activity in Figure 4 varied from one programming site to the next because of the differing activities delivered by the facilitator. Facilitators were given a choice of financial education activities that they could use with participants. All the choices were from a group of activities that were either developed by Idaho Extension educators as part of the Northwest Youth Financial Education series or youth education materials that have been adapted from other state Extension programs by Idaho Extension educators. The learning objectives for each activity are not identical, although all focus on financial management strategies such as budgeting, identifying wants versus needs, credit card use strategies, credit score management and strategies to manage college expenses. 


\section{Figure 4. Survey of Learning Objectives of Financial Education Activity}

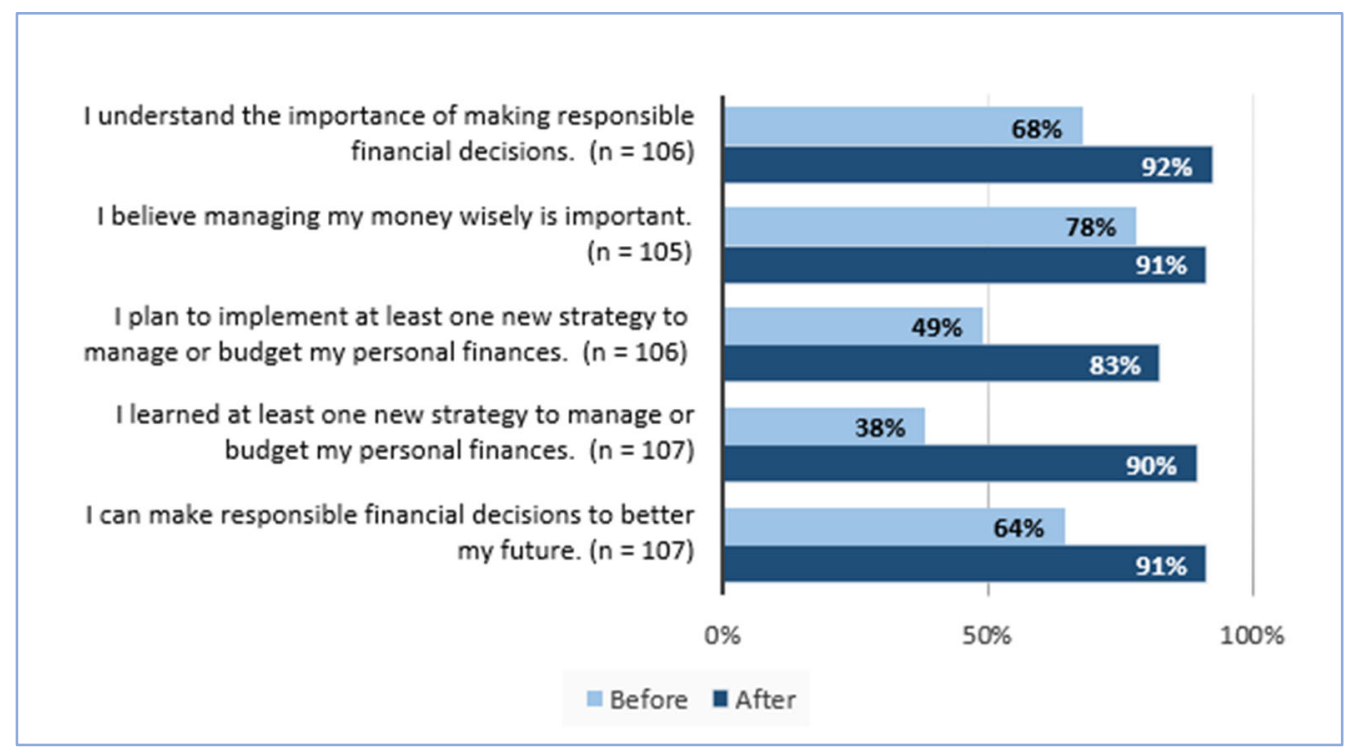

Overall, the survey results indicate an exceptionally high percentage of the participants agreeing or strongly agreeing that they understood or were aware of concepts presented as related to their personal areas of interest, career options, level of education required for their desired career, and strategies to pay for postsecondary education. Based on Hossler \& Gallagher's (1987) model, increasing youth's awareness should lead to increasing their predisposition to seek a postsecondary education, leading to a better-educated workforce. This could be applicable in other states and other college prep programs that adapt/adopt Idaho's Build Your Future program format.

Survey indicators related to actual steps taken showed a lower percentage of youth who accomplished tasks towards further career planning. Specifically, a much smaller percentage of youth indicated that they had collected letters of reference for their portfolio, created their portfolio, or created a plan to pay for their postsecondary education. These action steps also take more time than what can be accomplished during a class period and requires interaction with others outside of class time to request letters of reference and collect more information regarding options to finance their postsecondary education. This is a point for the program managers to consider how to motivate program participants from understanding to action and provide a follow up time with the youth. 


\section{Implications}

There are a variety of things to consider when implementing the BYF program. Research indicates that finding and maintaining a key person who facilitates any intervention program like BYF is imperative (Gandara \& Bial, 1999). This key person provides the program elements and builds a positive adult-youth relationship with a focus on exploring postsecondary education options. Building these positive relationships takes time and finding an adult willing to not only provide the program, but also help monitor and guide youth over a long period of time can be a challenge.

A unique aspect of the Idaho 4-H Build Your Future Program is the exploration of personal interests. Youth explore their personal interests while completing Activities 1 and 2 of the National 4-H Build Your Future curriculum and therefore begin to find a career pathway that they will likely enjoy. The University of Idaho McClure Center for Public Policy Research found that "having a job I love" is a high priority for Idaho youth (Henscheld \& McHugh, 2017). Further, the program addresses how much education youth need for a given career path. Without addressing the expected education level, youth can have "unaligned ambitions" which can affect what institutions and programs they may want to attend (Schneider et al., 2013).

As a part of exploring careers of interest, BYF participants interview or job shadow people working in careers of interest. In rural locations it can be difficult to find workers in specific careers. One option to address this difficulty includes video conferencing with people who are employed in occupations of interest. In some cases, workers may be able to travel to the program site and meet with the whole group to answer specific questions about their occupation.

Depending on the extent of the program, cost can be an issue in implementation. Students report that visiting a college campus is most influential in their decision to go to college (Cates \& Schaefle, 2011). Transporting students to a local college or university and providing them with a quality program while on campus can be expensive. Because our specific program utilizes the National 4-H curriculum, "Build Your Future: Skills . . Choices . . Careers," cost of providing curriculum can also be expensive.

This program combined several components found in a variety of literature reviews that should be included in postsecondary education programs. These components include visiting a college campus (Cates \& Schaefle, 2011), financial education (Scheider et al., 2013), youth's interests 
(Schneider et al., 2013), potential career income (Henscheld \& McHugh, 2017), and the support of mentors and peers (Gandara \& Bial, 1999). The Idaho BYF program managers feel that the benefits of implementing a postsecondary education program such as this one may far outweigh the challenges of time, rural isolation, and cost.

Addressing the concerns of youth considering postsecondary education is the goal of many goon programs. Determining whether these programs attain their goal is more difficult. A longitudinal study looking at the long-term effects of the various elements in any program can better inform which elements are most helpful to youth considering their options after high school. The report of National Postsecondary Education Cooperative Working Group on Access to Postsecondary Education (Gandara \& Bial, 1999) recommends that programs such as this take the following steps:

1. Collect baseline data on program participants and comparisons.

2. Monitor and report program attrition.

3. Carefully match control groups and report differences.

4. Measure the outcomes that the program purports to be affecting.

5. Attend to program features and outcomes.

Thousands of early intervention programs exist across the nation. However, the report indicates that data are generally sparse about where, for whom, and under what circumstances these programs work (Gandara \& Bial, 1999). Therefore, we believe further studies pursuing these recommendations would be beneficial for program development to determine what elements are most effective in encouraging youth to consider postsecondary education.

\section{References}

Barrett, D., Cox, F., Duvall, B., Jamieson, K., Jaros, A., Keinath, S., Payk, M., Radloff, D., Rivetto, L., Suszek, S., \& Zerbe, J. (2013). Build your future choices . . connections . . careers. Michigan State University Extension.

Cates, J., \& Schaefle, S. (2011). The relationship between a college preparation program and at-risk students' college readiness. Journal of Latinos and Education, 10(4), 320-334.

Clark, L. (2018). Idaho's "go-on" numbers showing progress. Idaho State Board of Education. https://boardofed.Idaho.gov/resources/Idahos-go-on-numbers-showing-progress/

Gandara, P., \& Bial, D. (1999). Paving the way to higher education: K-12 intervention programs for underrepresented youth. National Postsecondary Education Cooperative. 
Journal of Youth Development | http://jyd.pitt.edu/ | Vol. 15 Issue 5 DOI 10.5195/jyd.2020.796 Connecting Careers and Postsecondary Education

Henscheld, J., \& McHugh, C. (2017). Life choices of high school seniors. Idaho Facts at a Glance, 8(1). University of Idaho McClure Center for Public Policy Research. https://www.uidaho.edu/Lmedia/UIdaho-Responsive/Files/president/direct-reports/mcclure-center/Idaho-at-a-Glance/IDGLAHS.pdf

Hossler, D., \& Gallagher, K. S. (1987). Studying student college choice: a three-phase model and the implications for policy makers. The Journal of the American Association of Collegiate Registrars and Admissions Officers, 62(3), 207-221.

Howard, G. S. (1980). Response-shift bias: A problem in evaluating interventions with pre/post selfreports. Evaluation Review, 4(1), 93-106.

Idaho Department of Labor. (2018) Projections of Idaho jobs by industry and occupation 2012 to 2022. (n.d.). https://labor.Idaho.gov/publications/2022-Idaho-Projections.pdf

Lerner, R. M., Lerner, J. V., \& Colleagues. (2013). The positive development of youth: Comprehensive findings from the 4-H study of positive youth development. Medford, MA: Institute for Applied Research in Youth Development. https://4-h.org/wp-content/uploads/2016/02/4-H-Study-ofPositive-Youth-Development-Full-Report.pdf

Schneider, B., Broda, M., Fudy, F., \& Burkander, K. (2013). Pathways to college and STEM careers: Enhancing the high school experience. New Directions for Youth Development, 140, 9-29. 